\title{
Failure Analysis and Experimental Research on the Structure of Key Parts of Safety Valves
}

\author{
Ye Dai , Huibing Zhang, Hanbo Zhang, Wenqiang Wei and Rui Liu \\ Harbin University of Science and Technology, School of Mechanical and Power Engineering, Heilongjiang Harbin 150080, China
}

\begin{abstract}
In order to design a safety valve with a high safety factor, on the basis of theoretical calculations and ANSYS analysis, stress analysis is performed on the key components of the new nuclear A48 safety valve under open and closed conditions to detect whether the safety valve fails. The natural frequency of the safety valve and the spring are respectively analyzed and tested for seismic performance. The spring parameters are calculated through spring design specifications to determine the method of spring failure calculation and analysis. A lateral deflection measurement bench was built to verify the correctness of the design method through experimental data and provide a reliable theoretical basis for the design of safety valves with high safety factors.
\end{abstract}

\section{Preface}

As an important consumable in nuclear power technology, the demand for nuclear-level valves has been continuously expanding, among which safety valves play a role of safety protection in the system and ensure that equipment does not cause accidents due to high pressure [1]. The design of nuclear safety valve with high safety factor has important practical significance for studying the localization of nuclear valve design.

The key components for the safety valve include: whether the structural vibration characteristics of the valve safety valve flow channel meet the seismic conditions, the lateral offset of the spring is experimented and tested, which lays a foundation for designing a safety valve with a high safety factor .

\section{Stress analysis of main pressure- bearing relief valve}

Valve body, disc, stem, seat, bolts and other structures are key components in the valve pressure in the work. The purpose of safety valve stress analysis is to verify its structure to meet the needs of production work. Apply a certain load on the valve body and other key components to analysis of the valve body deformation and stress conditions[2]. In the main parts of the safety valve, the allowable stress value of the valve body is the minimum[3]. Taking the valve body as an example, the structural stress analysis process is analyzed, and the other parts and components are analyzed emphatically.

\subsection{Establishment of valve body finite element analysis model}

Before calculating the stress of the valve body, the finite element model of the valve body is first constructed[4-5]. Body solid model and finite element model shown in Figure 1 and Figure 2.

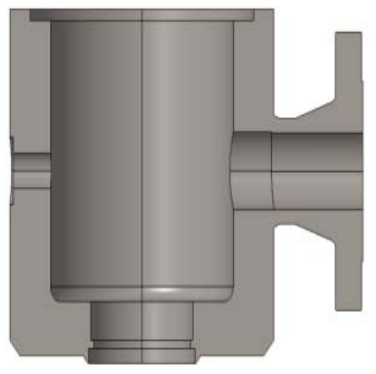

Fig. 1. Body model diagram.

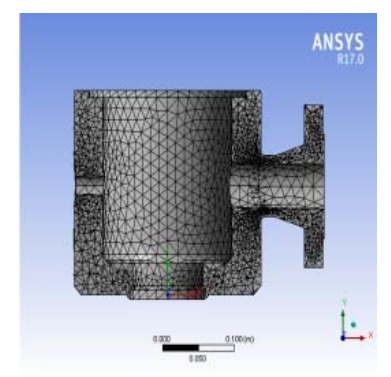

Fig. 2. Body finite element model diagram.

\subsection{Body load loading}

According to the ASME Technical Specification[6] 12FW088-001-BG Rev. A Appendix B requirements, to class D working load, according to Class B conditions criteria assessment, if the valve is qualified, it can be prove that the valve to meet the $\mathrm{B}, \mathrm{C}, \mathrm{D}$ grade workers condition. According to the D-class working conditions, 
the valve body pressure load from table 1 shown: Ps (secondary pressure), DW (dead-weight), SSE (safety shutdown earthquake), XL (external mechanical load), $\mathrm{OE}$ (equipment operating load).

(1) Seismic load

During the earthquake, the seismic loads on the bolts at the top of the valve body are transmitted to the bolts by the top parts of the valve body (including the guide sleeve, spring, spring cover, etc.). The load is equal to $6 \mathrm{~g}$ acceleration horizontally and $5 \mathrm{~g}$ acceleration to the vertical direction to the above components(remove the effect of gravity on the upper parts of the valve body). Taking a 1.1-fold safety factor, the resulting bolt forces at the top of the valve body are analyzed as follows:

Where $F_{X}=F_{Z}=76674 N, F_{y}=63894 N$, the equivalent force of $\mathrm{X}, \mathrm{Z}$ directions of the same bolt is synthesized as the resultant force $\mathrm{F}_{\mathrm{XZ}}$ along the horizontal direction.

$$
F_{X Z 1}=F_{X Z 2}=F_{X Z 3}=F_{X Z 4}=14911 \mathrm{~N}
$$

Seismic load equivalent bolt $\mathrm{X}$-direction and $\mathrm{Z}$ direction Torque:

$$
M_{X Z}=F_{X Z} \times L=11927.5 \mathrm{Nmm}
$$

The center of gravity of the top part is located on the top of the valve body bolt $\mathrm{L}=799.9 \mathrm{~mm}$

Apply $M_{X Z}$ to the top of the bolt of the valve body equally, because the force and torque of each bolt is different, each bolt are calculated separately to ensure that the torque is equal, as shown in Figure 3:

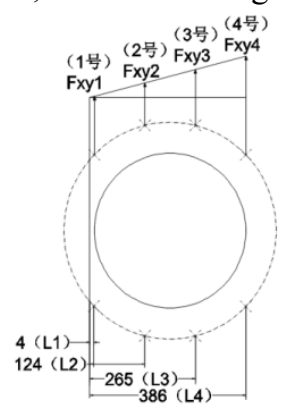

Fig. 3. Body bolt torque equivalent diagram.

The result is:

$F_{x y l}=102 N, F_{x y 2}=3187.5 N, F_{x y 3}=6757.5 N, F_{x y 4}=9843 N$.

(2) Impact load

Under the open condition, the valve stroke control ring has a great impact on the small guide sleeve of the cooler when the valve starts to jump. The impact will be passed through the cooler to the top of the bolt body. According to the CFX simulation analysis results, the impact load is $353252.4 \mathrm{~N}$, loading equally to each bolt:

$$
F=44157 N
$$

When closed, the valve flap has an impac $t$ on the body assembly when the valve is closed, and the impact is transmitted through the valve seat to the threaded surface where the valve body is connected to the valve seat. According to the calculation result, the impact load is:

$$
F_{\text {import }}=W_{l} \times g-P_{h} \times S=10329 \mathrm{~N}
$$

In the formula, $\mathrm{S}$ refers to the area of the medium effect.

(3) Medium force

The medium force inside the valve body of the $\mathrm{Y}$ direction of the guide sleeve is transferred to the bolt through the guide sleeve and cooler.

$$
F_{\text {medium }}=P S \times S / 8=40446 \mathrm{~N}
$$

In the formula, $S$ refers to the effective area of the medium acting on the guide sleeve, the size is: $S=17291 \mathrm{~mm}^{2}$

\subsection{Body stress analysis results and judgements}

Figure 4 shows the stress analysis of the open condition, Figure 5 shows the stress analysis of the closed condition.

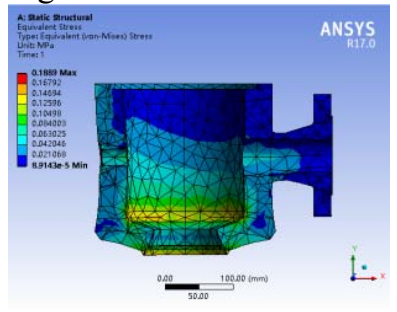

Fig. 4. open condition stress analysis.

Figure 6 shows the results of stress analysis of open condition curves, and Figure 7 shows the results of stress analysis of closed conditions.

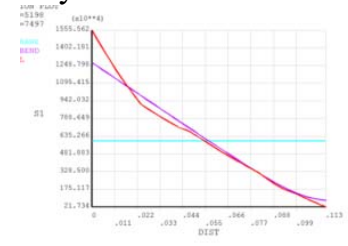

Fig. 6. Open condition stress assessment analysis.

Body stress assessment results in Table 2:

Table 1. body load conditions and load combination criteria.

\begin{tabular}{|c|c|c|c|}
\hline $\begin{array}{c}\text { Working } \\
\text { conditions }\end{array}$ & Load combination & Seismic requirements & $\begin{array}{c}\text { Design requirements } \\
\text { (assessment criteria) }\end{array}$ \\
\hline Dlevel & Ps+DW+SSE+XL+OE & $6 \mathrm{~g}, 6 \mathrm{~g}, 6 \mathrm{~g}$ & $\sigma_{\mathrm{m}} \leqslant \mathrm{S}$ \\
$\sigma_{\mathrm{m}}+\sigma_{\mathrm{b}} \leqslant 1.5 \mathrm{~S}$ \\
\hline
\end{tabular}

Table 2. Open - closed condition of the body stress.

\begin{tabular}{|l|l|l|l|}
\hline Condition & Stress Analysis $(\mathrm{MPa})$ & Allowable stress value $(\mathrm{MPa})$ & Conclusion \\
\hline \multirow{2}{*}{ Opening condition } & $\mathrm{P}_{\mathrm{L}}=5.941$ & $1.0 \times \mathrm{S}=1.0 \times 138=138$ & Qualified \\
\cline { 2 - 4 } & $\mathrm{P}_{\mathrm{L}+} \mathrm{P}_{\mathrm{b}}=12.75$ & $1.5 \times \mathrm{S}=1.5 \times 138=207$ & Qualified \\
\hline Shutdown condition & $\mathrm{P}_{\mathrm{L}}=7.282$ & $1.0 \times \mathrm{S}=1.0 \times 138=138$ & Qualified \\
\hline
\end{tabular}




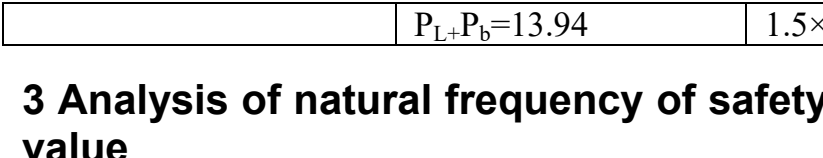

Due to the harsh environment inside the safety valve pipeline, the medium is generally hot and corrosive. In order to meet the structural requirements, it is necessary to test its performance in harsh working conditions[7], consider the safety valve performance under turbulent environment, analyze natural frequencies and calculate safety Seismic capacity of the valve[8].

\subsection{To establish a finite element model}

When modeling the safety valve with ANSYS 17 software, the structural simplification[9] is performed while maintaining the accuracy of the calculation. That is, the main components such as the valve seat, the valve body, the valve disc assembly, the guide sleeve, the spring cover, the valve stem, the crankshaft modeled, and ignore the spring, upper spring seat, lower spring seat and other internal parts, also remove the external connection flange structure. Add their mass approximation to the bottom of the valve body. Such an approximation will make the calculated natural frequency low.

Figure 8 (a), (b) for the safety valve solid model, Figure 8 (c) for the safety valve finite element model.

\subsection{Modal analysis pre-treatment}

(1) Table 3 shows the model material properties of the main parts of safety valve, including the elastic modulus, poisson's ratio and equivalent density. The quality of the spring, the upper and lower spring cover equivalent to the \begin{tabular}{l|l}
$.5 \times 138=207$ & Qualified \\
\hline
\end{tabular}

bottom of the valve body, the total safety valve $600 \mathrm{~kg}$ remain unchanged.

(2) Constraint conditions

Select the same restriction method with the general safety valve, adding constraints: the full constraint of raised face flange of valve body inlet, the adhesive constraints of body and guide sleeve, spring cover and adjusting screw, adjusting screw and stem, stem and valve assembly, the spring cover and the small cover, the valve disc assembly and the valve seat, and the bolt connection constraints of the valve body and the cooler, the cooler and the spring cover. And the valve as a whole exert gravity constraints.

\subsection{Safety valve natural frequency calculation results}

The first four orders of natural frequency of the nucleargrade A48 safety valve are shown in Table 4.

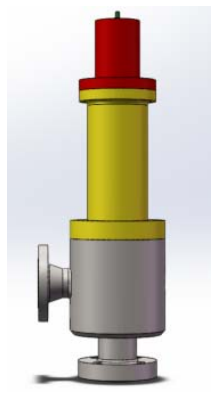

a) Safety valve solid model

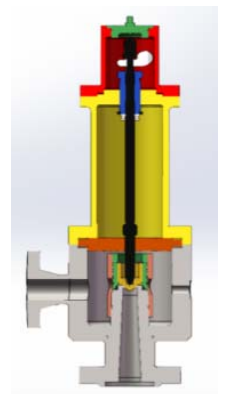

b) Safety valve solid profile model

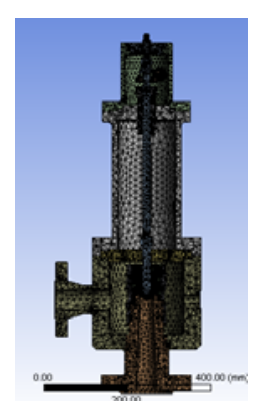

c) Safety valve finite element model

Table 3. Safety valve model material properties.

\begin{tabular}{|c|c|c|c|c|c|}
\hline Part Name & Material & Modulus of elasticity $(\mathrm{Pa})$ & $\begin{array}{l}\text { Poisson's } \\
\text { ratio }\end{array}$ & $\begin{array}{l}\text { Equivalent } \\
\text { density }\end{array}$ & $\begin{array}{l}\text { Equivalent } \\
\text { distribution }\end{array}$ \\
\hline Seat & $12 \mathrm{Cr} 1 \mathrm{MoV}$ & \multirow{8}{*}{$\begin{array}{l}\text { The approximate structure of the } \\
\text { structure depends on the natural } \\
\text { frequency } \\
2.03 \mathrm{e} 11\end{array}$} & \multirow{8}{*}{ Take 0.3} & 7800 & Nozzle seat itself \\
\hline Body & ZG20CrMoV & & & 7800 & Body itself \\
\hline Cooler & $20 \mathrm{~g}$ & & & 7800 & $\begin{array}{l}\text { With exhaust } \\
\text { chamber quality }\end{array}$ \\
\hline $\begin{array}{l}\text { Spring } \\
\text { cover }\end{array}$ & WCB & & & 7800 & Spring cover itself \\
\hline Crankshaft & WCB & & & 7800 & Crankshaft itself \\
\hline Valve stem & $1 \mathrm{Cr} 17 \mathrm{Ni} 2$ & & & 7800 & $\begin{array}{l}\text { With horizontal } \\
\text { pin and so on }\end{array}$ \\
\hline $\begin{array}{l}\text { Guide } \\
\text { sleeve }\end{array}$ & $1 \mathrm{Cr} 11 \mathrm{MoV}$ & & & 7800 & Guide sleeve itself \\
\hline Disc & $12 \mathrm{Cr} 1 \mathrm{MoV}$ & & & 7800 & $\begin{array}{l}\text { Valve with valve } \\
\text { components }\end{array}$ \\
\hline
\end{tabular}

Table 4. Natural frequency of the first 4 order.

\begin{tabular}{|l|l|l|}
\hline Frequency order & Frequency $(\mathrm{Hz})$ & Vibration type \\
\hline 1 & 168.44 & The whole is perpendicular to the direction of the pipe \\
\hline 2 & 289.77 & The whole parallel to the direction of the pipe \\
\hline 3 & 625.04 & Internal valve stem swinging (limited) \\
\hline 4 & 645.41 & Internal valve stem swinging (limited) \\
\hline
\end{tabular}

Figures 9-12 show the modal shapes for each step. 
Fig. 9 and Fig. 10 show that the first and second order mode shapes are bending modes and the mode shapes are orthogonality. Safety valve first-order natural frequency is $168.44 \mathrm{~Hz}$, greater than $33 \mathrm{~Hz}$, in line with safety requirements.

\section{Safety valve spring failure analysis}

Combined with specific experiments, the horizontal deviation straightness of the spring in the safety valve was tested and analyzed, and the experimental results were analyzed, and the calculation method was summarized[10].

\subsection{Safety valve spring mode analysis}

The finite element model of the safety valve spring is established, the natural frequency of the spring is analyzed[11], and the first four modes of the spring are shown in Fig. $13 \sim 16$.

As can be seen in Figure 13 and Figure 14, the firstorder and second-order modes of the spring are flexural mode and the spring modes are orthogonality. Figure 16 shows that fourth-order formations are torsional modes.
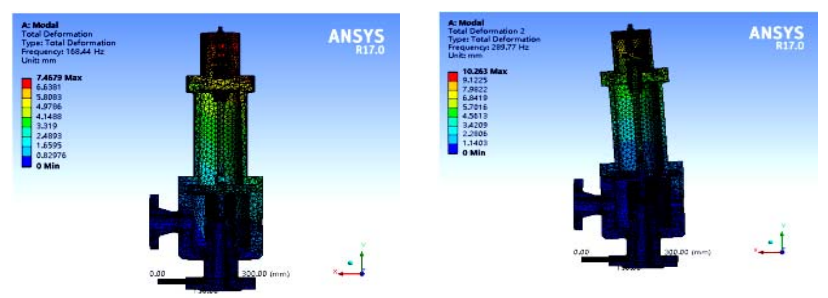

Fig. 9. First-order mode shapes.

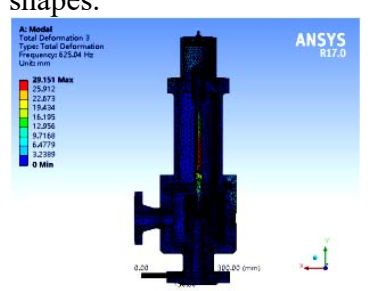

Fig. 11. Third-order mode shapes.

Fig. 10. Second-order mode shapes.

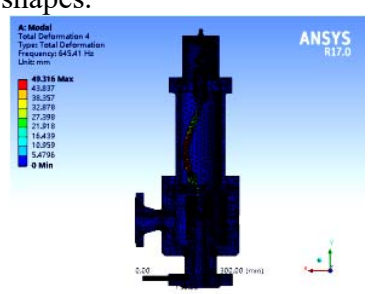

Fig. 12. Fourth-order mode shape.
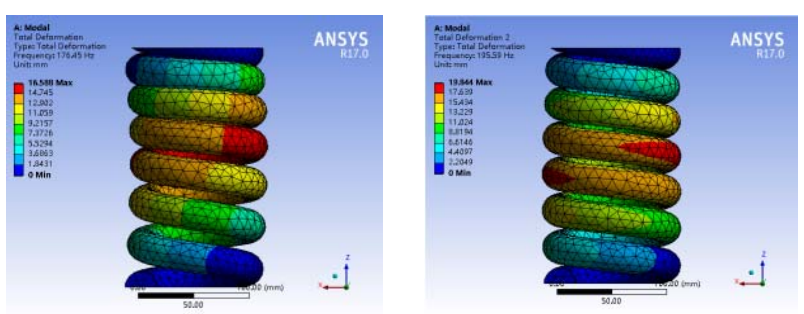

Fig. 13. First-order spring mode shape.

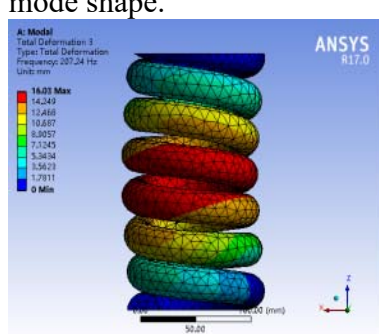

Fig. 15. Spring third-order mode shape.

Fig. 14. Spring second-order mode shape.

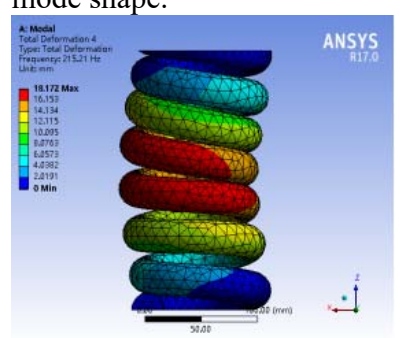

Fig. 16. Spring Fourth Mode Mode Shape.

\subsection{Safety valve spring lateral offset experiment}

As shown in Fig. 17, setting the horizontal deflection test bench of the spring is the important way to check if the spring is failed[12]. Through the fixed spring, the load is applied to measure the lateral deflection and straightness under spring load.

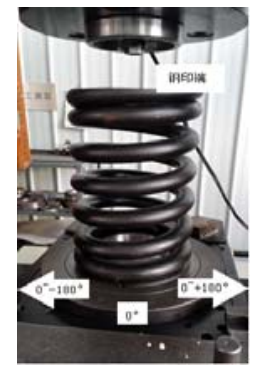

Table 5. under spring load lateral offset and straightness test results.

\begin{tabular}{|l|l|l|l|l|l|l|}
\hline Numbering & $\begin{array}{l}\text { P1 Load lateral } \\
\text { offset angle }\end{array}$ & $\begin{array}{l}\text { P1 Load } \\
\text { Lateral Offset }\end{array}$ & $\begin{array}{l}\text { P1 load } \\
\text { straightness }\end{array}$ & $\begin{array}{l}\text { P2 Load lateral } \\
\text { offset angle }\end{array}$ & $\begin{array}{l}\text { P2 Load } \\
\text { lateral offset }\end{array}$ & $\begin{array}{l}\text { Load } \\
\text { straightness }\end{array}$ \\
\hline $1 \#$ & $176.6^{\circ}$ & 3.04 & 0.2 & $-177.3^{\circ}$ & 1.27 & 0.8 \\
\hline $2 \#$ & $-145.7^{\circ}$ & 3.32 & 0.5 & $-103.1^{\circ}$ & 1.99 & 2.5 \\
\hline $3 \#$ & $-59.9^{\circ}$ & 1.62 & 0.8 & $-27.2^{\circ}$ & 3.0 & 3.3 \\
\hline
\end{tabular}

Figures 18 shows test results of different characteristics of the safety valve spring to be tested by operating the test bench readings. 


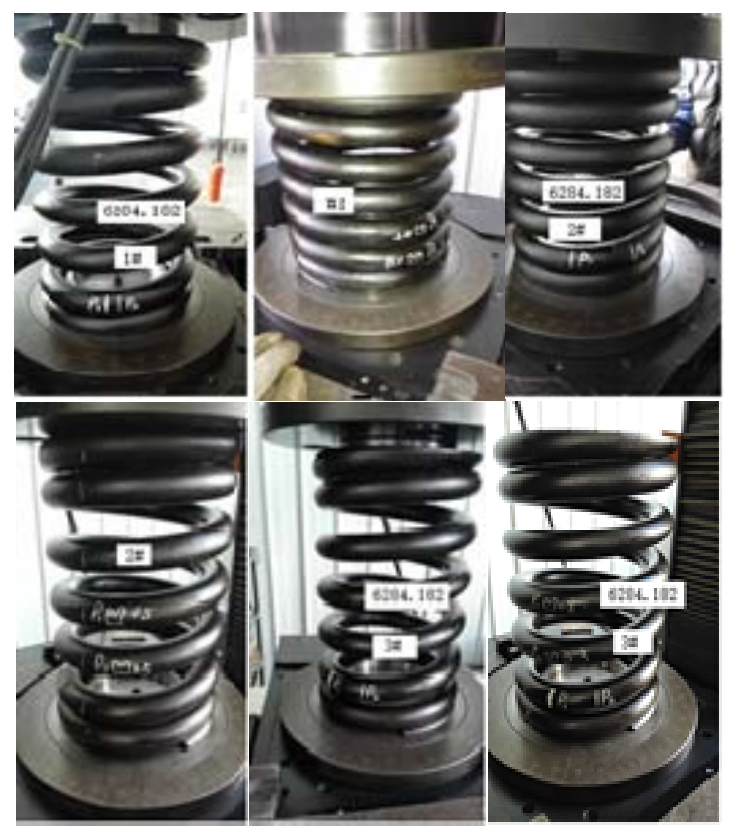

Fig. 18. Detection of different characteristics of the spring.

Detect the spring compression offset and straightness values to determine whether the valve stem to the force is too large, and whether spring failure. In order to prevent the failure of the spring, try to avoid being overloaded. For example, when the valve stem, the spring and the valve body are assembled together, this three are required to be coaxial and straight, so as to reduce the eccentric load and the safety stress value improve. The increase of the safety stress not only prolongs the service life, but also prevents the failure of the spring. In order to prevent spring failure, we should start from the control pressure. The pressure is stable, reducing the number of times of opening and closing of the safety valve to improve work efficiency and increase factory efficiency.

\section{Conclusion}

The failure analysis of the new nuclear safety valve is carried out. The stress of the main pressure parts is analyzed by ANSYS software. Taking the valve body as an example, the different working conditions are analyzed and tested, and the qualification of the main pressure parts is confirmed. The natural frequency of the safety valve is analyzed and researched, and its requirements of seismic resistance are tested. Finally, the failure analysis of the spring valve components is carried out. The natural frequencies and mode shapes of the safety valve are analyzed by simulation and the spring failure conditions of the safety valve are discussed through theoretical calculation. Finally, the lateral deflection test bench is set up to carry out experimental analysis to detect the failure of the spring, which shows that the experimental data can verify the correctness of the theoretical calculation and provide the research foundation for the safety valve failure analysis.

The research is supported by National Natural Science Foundation of China (Grant No. E51505109), University
Nursing Program for Young Scholars with Creative Talents in Heilongjiang Province (Grant No. UNPYSCT -2017077), China Postdoctoral Science Foundation (Grant No.2016M591539), Heilongjiang Postdoctoral Science Foundation (Grant No.LBH- Z15102).

\section{References}

1. Rundo M, Altare G, Olivetti M. 3D Dynamic Simulation of a Flow Force Compensated Pressure Relief Valve: ASME 2016 International Mechanical Engineering Congress and Exposition, 2016[C].

2. Galbally D, García G, Hernando J, et al. Analysis of pressure oscillations and safety relief valve vibrations in the main steam system of a Boiling Water Reactor[J]. Nuclear Engineering \& Design, 2015,293(3):258-271.

3. Zhai Xiao, Yu Shurong.Discussion on stress classification and strength evaluation of valve body [J] .fluid Machinery, 2011, 39 (1): 32-35.

4. YU Shurong, SONG Wei, HUO Ju, et al.Analysis and structural optimization of large-caliber gate valve body $[\mathrm{J}]$.Zhouzhou Polytechnic University, 2007, 33 (5): 64-66.

5. Gong Shuguang. ANSYS engineering application examples [M]. Machinery Industry Press, 2003.

6. ASME SECTION IX, Standards W I, Kỹ Thuật Công Nghệ, et al. 2007 ASME Boiler \& Pressure Vessel Code[J]. Tailieu Vn.

7. Li Jianfeng, Xu Hong, Wang Nan, et al. Analysis of seismic response of equipment by spectrum analysis [J] .Journal of Beijing University of Chemical Technology (Natural Science Edition), 2003, 30 (1): 57-60.

8. Zhang Yi, Qian Jiang. Seismic performance analysis and assessment of nuclear safety valve structure [C] // National Conference on Seismic Reinforcement and Retrofit Technology. 2009: 113-115.

9. Dai Ye, Lai Yi-nan, Zhang Yuan, et al.A quick and simplified method for model simplification based on rules and fuzzy decision [J]Journal of Harbin University of Science and Technology, 2013,18 (4): 37-41.

10. Bazsó C, Hős C J. An experimental study on the stability of a direct spring loaded poppet relief valve $[\mathrm{J}]$. Journal of Fluids \& Structures, 2013,42:456-465.

11. Xue G S, Lei C, Park Y C. Three-Dimensional CFD Analysis of a Spring-Loaded Pressure Safety Valve From Opening to Re-Closure[C]// ASME 2010 Pressure Vessels and Piping Division/K-PVP Conference. 2010:295-303.

12. Song X, Cui L, Cao M, et al. A CFD analysis of the dynamics of a direct-operated safety relief valve mounted on a pressure vessel[J]. Energy Conversion \& Management, 2014, 81(2):407-419. 